\title{
A gestão da comunicação no processo de racionalização do trabalho: os ditames de relações públicas no Brasil e na França (anos 1930-1960)'
}

The management of communication in the process of rationalization of the work: the dictates of public relations in Brazil and in France

La gestión de la comunicación en el proceso de la racionalización del trabajo: los dictados de las relaciones públicas en Brasil y Francia (años 1930-1960)

\section{Claudia Nociolini Rebechi}

- $\quad$ Doutora e mestre em Ciências da Comunicação pela Escola de Comunicações e Artes da Universidade de São Paulo (ECA-SP)

- $\quad$ Especialista em Gestão Estratégica em Comunicação Organizacional e Relações Públicas pela ECA-USP

- $\quad$ Graduada em Comunicação Social - Relações Públicas pela Universidade Estadual Paulista "Júlio de Mesquita Filho" (Unesp)

- $\quad$ Pesquisadora do Centro de Pesquisa em Comunicação e Trabalho (CNPq/ECA-USP)

- $\quad$ Professora do Departamento de Comunicação, no Centro de Educação, Comunicação e Artes (Ceca) da Universidade Estadual de Londrina (UEL)

- E-mail: nociolini@hotmail.com

1 Este artigo baseia-se em nossa tese de doutorado, "Prescrições de comunicação e racionalização do trabalho: os ditames de relações públicas em dialogo com o discurso do Idort (anos 1930-1960)", desenvolvida com o apoio da Fundação de Amparo à Pesquisa do Estado de São Paulo (Fapesp) e defendida em 2014 no Programa de Pós-Graduação em Ciências da Comunicação, da Escola de Comunicações e Artes da Universidade de São Paulo (ECA-USP), sob a orientação da Profa. Dra. Roseli Aparecida Fígaro Paulino. Ela foi laureada com o 10 lugar entre as teses, no Prêmio Abrapcorp de Teses e Dissertações 2015, conferido no IX Congresso Brasileiro Científico de Comunicação Organizacional e de Relações Públicas, realizado em Campinas (SP) de 13 a 15 de maio de 2015. 


\section{ANO 12 • NÚMERO 23 • 2으. SEM. 2015 - ORGANICOM A GESTÃO DA COMUNICAÇÃO NO PROCESSO DE RACIONALIZAÇÃO DO TRABALHO: OS DITAMES DE RELAÇÕES PÚBLICAS NO BRASIL E NA FRANÇA (ANOS 1930-1960)}

\section{Resumo}

Este artigo apresenta uma breve exposição da pesquisa de doutorado da autora, constituída por uma ampla investigação em arquivos brasileiros e franceses e realizada com o principal propósito de identificar e analisar as prescrições de relações públicas em diálogo com o discurso da racionalização do trabalho, difundido entre os anos 1930-1960. Sobretudo, a pesquisa trata dos ditames que nortearam a gestão da comunicação nas relações de trabalho em organizações na primeira metade do século XX. Naquele período, as formas de gerir o trabalho nas sociedades capitalistas foram orientadas pelos princípios do ideário taylorista/fordista e da Escola das Relações Humanas. Neste contexto de racionalização do trabalho, os ditames de gestão da comunicação em organizações foram influenciados por esses mesmos princípios, produzindo prescrições que procuravam mediar as relações de trabalho.

PALAVRAS-CHAVE:GESTÃO DACOMUNICAÇÃO •RACIONALIZAÇÃO DO TRABALHO • PRESCRIÇÕES DE RELAÇÕES PÚBLICAS•BRASIL•FRANÇA.

\section{Abstract}

This article provides a brief presentation of the author's doctoral research, consisting of extensive research in Brazilian and French archives and developed with the main purpose of identifying and analyzing the prescriptions of public relations in a dialogue with the discourse of rationalization of work, diffused in the course of the years 1930 to 1960. More than anything the research addresses the dictates that guided communication management in the working relations within organizations during the first half of the twentieth century. At that time the ways for management of the work in capitalist societies were guided by the principles of the taylorist/fordist ideas and of the Human Relations School. In this context of rationalization of work, the communication management dictated in organizations was influenced by these same principles, producing prescriptions that sought to mediate the work relations.

KEYWORDS: COMMUNICATION MANAGEMENT • RATIONALIZATION OF WORK •PRESCRIPTIONS OF PUBLIC RELATIONS•BRAZIL・FRANCE.

\section{Resumen}

En este artículo se presenta una breve presentación de la investigación doctoral de la autora, que consiste en una amplia investigación en los archivos brasileños y franceses y realizado con el objetivo principal de identificar y analizar los requisitos de las relaciones públicas en el diálogo con el discurso de la racionalización del trabajo, extendido entre los años 1930-1960. Por encima de todo, la investigación se ocupa de los dictados que guiaron la gestión de la comunicación en las relaciones laborales en las organizaciones en la primera mitad del siglo XX. En ese momento, la manera de gestionar el trabajo en las sociedades capitalistas se guía por los principios de las ideas taylorista/fordista y la Escuela de Relaciones Humanas. En este contexto de racionalización del trabajo, la gestión de la comunicación en las organizaciones dicta fueron influenciados por estos mismos principios, la producción de recetas que intentan mediar en las relaciones laborales. 


\section{ANO 12 • NÚMERO 23 • 2은. 2015 - ORGANICOM A GESTÃO DA COMUNICAÇÃO NO PROCESSO DE RACIONALIZAÇÃO DO TRABALHO: OS DITAMES DE RELAÇÕES PÚBLICAS NO BRASIL E NA FRANÇA (ANOS 1930-1960)}

$\mathrm{N}$

a primeira metade do séculoXX, os princípios da racionalização do trabalho, representados pelas filosofias taylorista/ fordista e da Escola das Relações Humanas, mostraram-se fundamentais na constituição das formas de gestão do trabalho em organizações. Conhecidos como parte integrante do ideário da Organização Científica do Trabalho, esses princípios foram difundidos amplamente em sociedades capitalistas com processos mais avançados de industrialização e também em outras que ainda estavam em fase inicial de desenvolvimento urbano-industrial, a exemplo do Brasil à época.

Em ambos os casos, a doutrina da racionalização do trabalho foi admitida pela classe dirigente - formada por empresários, intelectuais e políticos-como a mais adequada para controlar a realização e a eficiência do trabalho nos ambientes produtivos e apaziguar os conflitos existentes nas relações de trabalho. Tendo isso em vista, entidades promotoras da racionalização do trabalho foram criadas em vários países com o propósito de difundir os preceitos da Organização Científica do Trabalho e de tentar convencer a opinião pública a aceitar os princípios da "administração científica" como os mais adequados para a administração de organizações.

Para desempenhar esse papel no Brasil, foi criado o Instituto de Organização Racional do Trabalho (Idort), que, entre as décadas de 1930 e 1960, mostrou-se bastante atuante. Dirigida e apoiada por membros da burguesia industrial, essa entidade procurou organizar e difundir um amplo conjunto de informações sobre a Organização Científica do Trabalho, além de possibilitar o compartilhamento de conhecimento entre os interessados na questão. Dentro dessa perspectiva, 0 Idort promoveu várias campanhas nacionais e organizou jornadas e congressos internacionais, bem como realizou diversas consultorias para empresas privadas e órgãos governamentais.

0 Idort, no entanto, não era uma entidade isolada no Brasil. Ao longo de sua trajetória, o instituto manteve uma relação estreita com entidades congêneres no exterior, por meio de sua integração ao movimento internacional de organização racional do trabalho, coordenado pelo Comité International de l’Organisation Scientifique (Cios), criado na década de 1930, em Paris. Não por acaso, na primeira metade do século XX, estabeleceu-se um intercâmbio de informações entre organismos nacionais semelhantes ao Idort, de diversos países, em torno da corrente de pensamento centrada no delineamento e na difusão da combinatória de métodos e princípios baseada nos ditames da Organização Científica do Trabalho, que, por sua vez, focalizava a criação de parâmetros "científicos" e "racionais" para a organização e a gestão do trabalho.

Tais parâmetros, propagados pelas entidades ligadas ao Cios, impuseram uma nova lógica às relações de trabalho nas empresas. Nessa direção, um arsenal de dispositivos foi instaurado a favor da racionalização dos processos produtivos, em especial aquele direcionado às relações entre indivíduos, grupos e classes no ambiente de trabalho. Uma nova conformação dos relacionamentos entre os diversos níveis hierárquicos mostrou-se essencial para o "bom" funcionamento das organizações, conforme a ótica do patronato. As relações entre chefias e subordinados, trabalhadores e o comando da empresa e entre os próprios trabalhadores ganharam uma nova dimensão.

Nessa perspectiva, as entidades promotoras da racionalização do trabalho, como o ldort, contribuíram para a produção e disseminação de novos modos de regulação social nas empresas, entre os quais aparece o uso da comunicação.

Por meio de um levantamento exaustivo de material produzido pelo ldort - textos de sua revista institucional e apostilas dos cursos de relações públicas promovidos por ele -, foi possível identificar um conjunto de prescrições que orientaram a gestão da comunicação nas relações de trabalhos em organizações da época. 
Ademais, a análise desse material revelou que as prescrições de comunicação em organizações difundidas pelo instituto brasileiro poderiam estar integradas a um discurso de racionalização compartilhado por outras entidades estrangeiras que atuavam de forma correlata a ele. A partir disso, optamos por concentrar nossos esforços, durante certo momento de nossa pesquisa, em identificar e analisar as prescrições de relações públicas e, consequentemente, de comunicação em empresas, disseminadas por duas entidades congêneres do Idort na França: o Comité National de l'Organisation Française (Cnof) e a Commission Générale d’Organisation Scientifique (Cegos). Durante nosso estágio doutoral (doutorado-sanduíche) na cidade de Paris, realizamos um aprofundado levantamento de textos sobre relações públicas publicados por ambas as entidades francesas. Coletado sobretudo na Bibliothèque Nationale de France (BnF), esse material revelou muitos pontos de contato entre os ditames presentes no discurso do Idort e das entidades francesas Cnof e Cegos.

Desse modo, os resultados de nossa pesquisa mostram que há convergências importantes entre as abordagens brasileira e francesa sobre a gestão da comunicação no trabalho, evidenciadas sobretudo no material analisado da década de 1950.

Nesse contexto, este artigo procura trazer informações fundamentais para o conhecimento e a compreensão dos ditames que nortearam a gestão da comunicação nas relações de trabalho em organizações, especialmente no Brasil, na primeira metade do século XX.

Trata-se de reflexões integrantes de nossa tese de doutorado, cujo propósito foi estudar as prescrições de comunicação em relação aos princípios da racionalização do trabalho, orientadores da principal lógica de organização e gestão do trabalho em empresas no Brasil, no período de 1930 a 1960, tendo por base o discurso do Instituto de Organização Racional do Trabalho (Idort).

As análises dispostas no estudo demonstram a plausibilidade de duas hipóteses que guiaram a tese: o desenvolvimento da atividade de relações públicas no Brasil recebeu influência dos princípios da racionalização do trabalho admitidos pelo Idort e a gênese das prescrições de comunicação nas relações de trabalho em organizações apresenta relação direta com os mesmos princípios. Para este artigo, optamos por apresentar e discutir, mesmo que de modo sucinto, os ditames que orientaram as prescrições de relações públicas identificados no material levantado, considerando que essas prescrições são representativas do modelo de gestão da comunicação nas relações de trabalho em organizações admitido na primeira metade do século XX.

Diante disso, a composição deste artigo apresenta três momentos. Inicialmente, mostramos o percurso de investigação da pesquisa em arquivos brasileiros e franceses. Em seguida, tratamos das filosofias de trabalho constituintes do processo de racionalização, que nortearam a gestão da comunicação nas relações de trabalho à época. E, por fim, discutimos parte das prescrições de relações públicas identificadas e analisadas em nossa tese.

\section{CONTEXTUALIZAÇÃO DA PESQUISA EM ARQUIVOS BRASILEIROS E FRANCESES}

Nosso estudo guiou-se, em grande medida, pela investigação em arquivos que oferecessem material suficiente para criarmos o corpus da pesquisa sobre as prescrições de comunicação em organizações no contexto da racionalização do trabalho.

Tendo isso em vista, tomamos conhecimento do "Fundo Idort", conservado pelo Arquivo Edgard Leuenroth (AEL) do Instituto de Filosofia e Ciências Humanas (IFCH) da Universidade Estadual de Campinas (Unicamp). Constituído por um extenso 
conjunto de documentos, doado pelo próprio Idort à Unicamp na década de 1980, esse acervo foi disponibilizado para consulta pública no início dos anos 1990, após ter sido inventariado sob a coordenação do professor, sociólogo e estudioso do mundo do trabalho Ricardo Antunes. A documentação contempla relatórios e correspondências da entidade com data entre 1931 e 1961, apostilas produzidas a partir dos cursos oferecidos pelo Idort (de temas variados) e sua participação em diversos eventos no período de 1934 a 1974. 0 AEL também guarda grande parte dos números da revista institucional publicada pelo Idort, desde 1932 até o final da década de 1950.

De todo esse material produzido pelo Idort, dois documentos mostraram-se fundamentais para a composição do corpus de nossa pesquisa: os textos sobre relações públicas inseridos na revista institucional do instituto e as apostilas produzidas com base nos cursos de relações públicas promovidos pela entidade.

Quanto à revista institucional do Idort, consultamos todos os números publicados entre 1932 e 1959. 0 AEL da Unicamp foi a principal fonte de levantamento do material no Brasil, mas não a única. Apesar de esse arquivo contemplar boa parte da coleção da revista do Idort, ele dispõe dos números publicados até o ano 1957. Com base nessa realidade, foi preciso consultar acervos de outras instituições para continuar a investigação, haja vista que o objetivo era realizar um levantamento de textos que contemplasse todos os números do periódico até o final da década de 1960. Desse modo, essa etapa continuou na Biblioteca da Faculdade de Economia, Administração e Contabilidade da Universidade de São Paulo (FEA-USP), onde pudemos acessar os números da revista publicados entre 1958 e 1969, com exceção dos anos 1963 e 1966 . Especificamente quanto a esses dois anos, ainda foi preciso consultar o acervo da Biblioteca do Instituto de Energia e Ambiente (IEE) da USP.

Já no que se refere às apostilas de relações públicas, identificamos doze delas, produzidas e difundidas nos anos 1950 e 1960, cujas referências são: (a) curso de iniciação às relações públicas (autoria: Mario Sassi); (b) curso de relações públicas (autoria: Celso Lobo da Costa Carvalho); (c) curso de relações públicas - nível I (autoria: Candido Teobaldo de Souza Andrade); (d) curso de relações públicas - nível II, duas versões com datas distintas, provavelmente porque o curso foi ministrado mais de uma vez (autoria: Candido Teobaldo de Souza Andrade); (e) curso de relações públicas - nível III, duas versões com datas distintas (autoria: Candido Teobaldo de Souza Andrade); (f) curso de relações públicas e comunicação com o pessoal (autoria: Candido Teobaldo de Souza Andrade e Joel Barbosa); (g) curso de relações públicas na Força Pública de São Paulo (autoria: Amaury Morais de Maria); (h) curso de relações públicas - duas apostilas com datas distintas, mas do mesmo autor (Amaury Morais de Maria); (i) curso de relações públicas (autoria: Rubens José de Castro Albuquerque).

Todo esse material levantado em acervos brasileiros, de fato pode ser considerado o principal corpus da pesquisa, pois é por meio dele que conseguimos criar um percurso de análise e de interpretação coerente com os objetivos e as hipóteses da tese.

A leitura desse material, no entanto, nos instigou a continuar mais um pouco esse trabalho de identificação e de coleta de documentos que poderiam contribuir para a discussão central da pesquisa. Enquanto tomávamos conhecimento da trajetória do Idort, soubemos que o instituto brasileiro participava ativamente do movimento mundial de racionalização do trabalho liderado inicialmente pelo Institut International d'Organisation Scientifique du Travail (liost), até 1934, e posteriormente pelo Comité International d'Organisation Scientifique (Cios). Tratava-se de um movimento que congregava várias entidades congêneres do Idort, de nacionalidades distintas, com o propósito principal de criar um discurso hegemônico sobre a racionalização por meio do intercâmbio de informações entre elas. Dentre as entidades estrangeiras, duas despertaram nossa atenção por demonstrarem interesse na atividade de relações públicas: o Comité National de l'Organisation Française (Cnof) e a Commission Générale d'Organisation Scientifique (Cegos). Ambas, entidades francesas, assim como o Idort e no mesmo 
período - anos 1950 e 1960 - desenvolveram ações para divulgar as relações públicas dentro do propósito da racionalização do trabalho, aliando o uso da comunicação que essa atividade propunha aos princípios da Organização Científica do Trabalho.

Diante disso, fizemos um estágio de pesquisa em Paris, para realizar um levantamento de documentos produzidos pelo Cnof e pela Cegos no que diz respeito às relações públicas². Ainda no Brasil, investigamos as bases digitais de acervos franceses e descobrimos a existência de material produzido pelas entidades disponível para consulta na Bibliothèque Nationale de France (BnF). Já em Paris, consultamos uma série de documentos produzidos pelo Cnof e pela Cegos e identificamos aqueles que tratam sobre relações públicas.

No caso do Cnof, seu periódico Revue mensuelle de l'organisation mostrou integrar textos diretamente relacionados ao assunto. Diante disso, realizamos a leitura de todos os números dessa revista mensal do período de 1950 a 1969 e separamos os textos que, à primeira vista, interessavam à pesquisa ${ }^{3}$.

Quanto à Cegos, descobrimos duas valiosas publicações de sua autoria, oriundas de jornadas de relações públicas que promoveu nos anos 1950. Trata-se de publicações que reúnem um conjunto de textos dos conferencistas que participaram desses eventos:

1) Les journées d'études de la Cegos: 20, 21, 22 avril 1953. Pratiques des relations publiques: experiénces. Paris: Éditions Hommes et Techniques, 1953.

2) Les journées d'études de la Cegos: 6 et 7 avril 1959. Techniques actuelles de relations publiques. Neuilly-sur-Seine: Éditions Hommes et Techniques, 1959.

O levantamento documental, tanto no Brasil como na França, foi fundamental no desenvolvimento da íntegra da pesquisa. Optou-se por explorar o corpus de modo que ele aparecesse como motriz das análises realizadas e como elemento imprescindível para a mobilização dos objetivos e das hipóteses do estudo ao longo do desenvolvimento da tese.

Decidiu-se pelo modo de tratamento desse material - parte do corpus da pesquisa integral - que não se limitasse ao ponto de vista já estabelecido por seu conteúdo. Tratar o corpus como um conjunto de textos que transmitem ideias pré-concebidas e procurar descrevê-los para ilustrar seus dizeres não seria suficiente para os objetivos e as hipóteses da pesquisa. Dentro dessa abordagem, é possível dizer que a forma escolhida para a mobilização do corpus, de certo modo, filia-se aos princípios gerais da análise do discurso de linha francesa, embora não seja uma pesquisa de análise do discurso stricto sensu.

A análise do discurso é admitida no desenvolvimento do percurso teórico-metodológico da pesquisa em questão devido ao olhar específico que ela coloca nos textos, mostrando a relevância de tentar compreendê-los dentro do contexto sociopolítico e ideológico que produz sua discursividade.

Pode-se afirmar que os princípios da análise do discurso se apresentam como significativos à medida que contribuem para a constituição de uma prática de leitura do material levantado coerente com os propósitos da pesquisa. Concordamos,

2 Nosso estágio de pesquisa doutoral na França foi financiado pela Fundação de Amparo à Pesquisa do Estado de São Paulo (Fapesp), por meio de concessão de bolsa de doze meses (proc. 2012/ 04335-4), de julho de 2012 a agosto de 2013.

3 A lista completa dos textos levantados nos acervos brasileiros e franceses está disponível em nossa tese de doutorado, que pode ser acessada em sua íntegra no website www.teses.usp.br. 
por exemplo, com a linguista Eni Orlandi, uma das principais difusoras dos conceitos da análise do discurso no Brasil, quando ela afirma que "a natureza dos materiais analisados, a questão colocada, as diferentes teorias dos distintos campos disciplinares - tudo isso constitui o dispositivo analítico" (Orlandi, 1999, p. 28).

A leitura dos textos levantados e uma análise inicial, dispostas a compreender esse material na sua integralidade, revelou uma convivência bastante curiosa entre a noção de relações públicas e os princípios da racionalização do trabalho, produzindo determinadas prescrições de comunicação na gestão do trabalho em organizações, que veremos mais adiante.

\section{A GESTÃO DO TRABALHO SOB A FILOSOFIA DA ORGANIZAÇÃO CIENTÍFICA DO TRABALHO}

As entidades promotoras da racionalização do trabalho propagavam a ideia de determinação "científica" das formas de organização e gestão do trabalho, pois consideravam que somente o planejamento e a realização do trabalho baseados em técnicas e princípios estabelecidos pela gerência e pelos controladores do capital seriam os mais eficientes para o aumento da produtividade dentro das empresas.

Conforme essa abordagem, a lógica de administração do trabal ho aceita e difundida pelo Idort e pelas entidades francesas Cnof e Cegos esteve baseada em ditames estabelecidos por uma certa racionalidade considerada a mais adequada aos objetivos de modernização das relações de produção. 0 ideário taylorista, nesse sentido, mostrou-se como a opção mais favorável aos interesses da classe industrial, numa ajustada compatibilidade com o projeto de expansão do capitalismo naquele momento.

Entretanto, outras doutrinas desenvolvidas e disseminadas, sobretudo na primeira metade do século XX, também foram reconhecidas pelas entidades promotoras da racionalização do trabalho como aliadas a uma ordem social, considerada necessária para o acúmulo de capital e para a industrialização do país. Duas delas mostraram-se importantes: 0 fordismo e a Escola das Relações Humanas. Trata-se de doutrinas que, juntamente com o taylorismo, mobilizaram ditames e técnicas motrizes desse intenso processo de racionalização do trabalho. No cruzamento de fundamentos e intenções em comum de tais formas de gestão e organização do trabalho, padrões e normas são estabelecidos pela sociedade.

É sabido que a doutrina da "administração científica" ou organização científica do trabalho, muito propagada pela expressão "taylorismo", em função de seu criador, o norte-americano Frederick Winslow Taylor (1856-1915), que estabeleceu, no final do século XIX, um ideário seguido e ratificado, em muitos de seus aspectos, por outras tendências.

Tendo em vista o propósito de aumentar o rendimento dos trabalhadores em prol do aumento da produtividade na empresa norte-americana em que atuava como contramestre - a Midvale Steel -, Taylor estabeleceu parâmetros para a organização e gestão do trabalho que seriam conhecidos e aplicados em outros organismos e em outros países, além dos Estados Unidos, tempos depois. Trata-se de princípios e métodos (técnicas) que fazem da "administração científica" um sistema racionalizador do trabalho com algumas distinções significativas dos sistemas de administração anteriores a ele.

Em sua obra mais célebre, intitulada Princípios da administração científica, Taylor esforça-se por sistematizar seu pensamento e apresenta ao leitor os fundamentos de sua filosofia, centrada especialmente na relação de "cordialidade" entre aqueles que "planejam" e os que "executam" o trabalho (Taylor, 2013). 
Recomenda-se, dentro da ótica taylorista, que cada tarefa a ser desempenhada pelo trabalhador seja inteiramente pensada pela gerência. Deve-se detalhar a tarefa ao especificar o que fazer, como fazer e em quanto tempo realizar. À direção é atribuída toda a responsabilidade de pensar, de antecipar a realização do trabalho de seus subordinados: "Quase todos os atos dos trabalhadores devem ser precedidos de atividades preparatórias da direção, que habilitam os operários a fazerem seu trabalho mais rápido e melhor do que em qualquer outro caso" (Taylor, 1978, p. 43).

Taylor compreendia o princípio da separação entre concepção e execução do trabalho como uma forma de "cooperação" entre a direção e o trabalhador, essencial à "administração científica". Enquanto a direção ficasse responsável por planejar o trabalho, os trabalhadores contribuiriam com a sua execução mais fiel possível às instruções recebidas, pois "um tipo de homem é necessário para planejar e outro tipo diferente para executar o trabalho" (Taylor, 1978, p. 52). Nessa perspectiva, simplifica-se o trabalho em instruções consideradas possíveis de serem compreendidas e assimiladas pelo trabalhador. 0 indivíduo, em última instância, é considerado um ser incapaz, intelectualmente, de pensar o processo de trabalho e de realizá-lo sem o auxílio da gerência.

Frederick W. Taylor insistia que a "administração científica" exige "cooperação íntima e cordial" na nova divisão de responsabilidades entre aqueles que planejam e os que devem executar o trabalho. Esse sistema compreenderia uma combinação complexa de elementos que demanda "harmonia, em vez de discórdia", "cooperação, não individualismo", enfim, "ciência, em lugar de empirismo" (Taylor, 1978, p. 128).

No caso do Brasil, quando se toma conhecimento do percurso do Idort, é de se supor que o taylorismo se difundiu por meio da atuação de industriais paulistas, a partir do começo dos anos 1930. Mas, conforme indica Nilton Vargas (1985), é a partir dos anos 1950 que os princípios tayloristas são apropriados, de modo mais evidente, pela classe dirigente nacional. Os aspectos do ideário taylorista eram considerados úteis para a elaboração de uma ideologia adequada à proposta de uma sociedade industrial, urbana, calcada no modelo capitalista e em suas exigências de produção e acúmulo de capital. A formação e a reprodução de mão de obra nacional era, dentro desse contexto, um dos elementos de maior interesse para a classe dirigente.

Outro engenheiro norte-americano e contemporâneo de Frederick W. Taylor também esteve interessado em criar fundamentos e métodos para submeter o trabalhador a modos de trabalhar extremamente racionalizados de maneira "consensual". Trata-se de Henry Ford (1862-1947), que, assim como Taylor, procurou criar parâmetros para planejar e controlar o processo de trabalho.

Significativo aspecto do ideário de Ford dizia respeito a como "educar" a mão de obra a fim de adaptá-la ao seu método de produção, que exigia grande disciplina e engajamento físico e psíquico do trabalhador para um melhor desempenho em termos de produtividade. As "iniciativas educativas" propagadas pelo fordismo, conforme expressão cunhada por Gramsci (2008), referem-se às maneiras pensadas pela classe empresarial para aumentar o dito "bem-estar" social da classe trabalhadora como uma maneira de conseguir mais engajamento de sua parte no rendimento do trabalho. Serviços sociais e atividades de recreação e lazer começaram a ser oferecidos aos trabalhadores na tentativa de impor a eles valores considerados adequados pela classe dirigente. Conforme lembra José Roberto Heloani (1994), o modelo fordista não se preocupava somente em disciplinar a força de trabalho dentro do espaço fabril, mas estendia-se até mesmo fora dele.

Assim como Taylor, Ford procurou aumentar a especialização das tarefas no trabalho, simplificando-as a tal ponto que qualquer pessoa poderia executá-las a partir de instruções, de normas emitidas pelos empregadores. Ambos se mostraram 
pouco valorizadores da especificidade humana na realização do trabalho e ignoravam o ponto de vista do trabalhador no processo de trabalho.

0 processo de racionalização do trabalho do sistema taylorista/fordista apresenta características de cunho essencialmente mecanicistas. Sob essa ótica, o ser humano é compreendido, sobremaneira, por meio de aspectos fisiológicos, econômicos e técnicos.

No período entre as Primeira e a Segunda Guerra Mundial, entretanto, as condições de trabalho e o trabalhador foram investigados em outra perspectiva. Para um grupo de pesquisadores norte-americanos interessava estudar o que chamaram de "fator humano" dentro do processo produtivo.

Uma série de experiências com o propósito de analisar o indivíduo no trabalho foram realizadas na usina de Hawthorne da Western Eletric Company, entre 1924 e 1932. Algumas dessas experiências foram dirigidas por engenheiros do Massachussetts Institute of Technology (MIT). As mais conhecidas delas são as investigações coordenadas por Elton Mayo, que, posteriormente, se tornariam referência para inúmeros estudos de sociologia do trabalho, sociologia industrial e psicossociologia.

Em especial, os experimentos de Mayo originaram a Escola das Relações Humanas, cujos fundamentos configuraram as diretrizes de gestão de pessoal associada às políticas do management, a partir dos anos 1940. Essa tendência buscava agir sobre o comportamento e a motivação dos trabalhadores a fim de explorar a dimensão social das relações entre os indivíduos e o sistema produtivo nas empresas (Desmarez, 1986).

0 trabalhador, na perspectiva das "relações humanas", deveria ser compreendido como um ser humano constituído de "sentimentos" e com necessidades "psicológicas" e "sociais" que ultrapassam necessidades econômicas e materiais, tais como o recebimento de um salário ou de gratificações financeiras relacionadas ao rendimento de seu trabalho (Pillon; Vatin, 2003). Tendo isso em vista, questões subjetivas como o comportamento e a motivação dos trabalhadores tornaramse centrais no contexto da racionalização do trabalho.

Aparentemente, pode-se supor que o movimento das "relações humanas" é considerado uma reação ou uma oposição aos princípios e métodos tayloristas. No entanto, Desmarez (1986), e Braverman (1987) questionam esse posicionamento. Ambos compreendem que tal perspectiva complementa a doutrina da "administração científica", pois ela não critica os fundamentos desse tipo de organização do trabalho, mas, sim, os meios de submeter os trabalhadores a essa lógica. 0 processo de organização e gestão do trabalho trazido pelo taylorismo é considerado algo inelutável. A preocupação de Elton Mayo e sua equipe seria, portanto, oferecer instrumentos para a "estão social" dos trabalhadores face ao modo de realizar o trabalho, num contexto já estabelecido pela "administração científica".

Pode-se dizer que, de modo adaptado aos contextos sociopolítico e econômico do Brasil e da França, todas essas filosofias de gestão do trabalho foram assimiladas e propagadas pelo ldort e pelas entidades francesas Cnof e Cegos, cujos princípios influenciavam as formas de gestão e organização do trabalho e de controle social das relações entre trabalhadores e a direção de empresas praticadas por parcela significativa do empresariado. Nesse sentido, o encontro do Idort, do Cnof e da Cegos com a atividade de relações públicas, sobretudo a partir dos anos 1950, mostrou-se representativo dentro desse cenário. 


\section{PRESCRIÇÕES DE RELAÇÕES PÚBLICAS NA GESTÃO DO TRABALHO}

Conforme indicado antes, a atuação similar e, sobretudo, dentro de um mesmo período histórico, do Idort e das entidades francesas Cnof e Cegos, na difusão dos princípios de relações públicas, não foi uma mera coincidência.

Pode-se dizer que o interesse comum dessas entidades promotoras da racionalização pelas relações públicas deu-se, principalmente, devido ao teor da natureza "conciliadora" dessa atividade que se formulava naquela época. A incorporação de princípios e métodos, alinhados às doutrinas da Organização Científica do Trabalho, por organizações privadas e governamentais, acirrava os conflitos no contexto da gestão do trabalho. Não surpreendentemente, os trabalhadores resistiram a certos modos de realização do trabalho e de comportamentos impostos a eles. Tendo isso em vista, a filosofia de "harmonização" admitida pelas relações públicas mostrava-se conveniente à necessidade do processo de racionalização de amenizar os embates nas relações internas aos espaços produtivos.

Seja no Brasil ou na França, o discurso sobre a relevância das relações públicas para a conformação de determinadas formas de gestão do trabalho, filiadas às doutrinas taylorista, fordista e da Escola das Relações Humanas, foi constituído com base em aspectos basilares da atividade difundidos em ambos os países. Mais especificamente na década de 1950 , influentes propagadores das relações públicas justificavam a coerência da filosofia das relações públicas aos princípios da racionalização do trabalho.

No caso do Brasil, por exemplo, o norte-americano Eric Carlson, consultor da Organização das Nações Unidas (ONU) e especialista em relações públicas, esteve no país em 1953, para ministrar cursos e conferências sobre o tema. Em conformidade com a configuração do entendimento sobre gestão do trabalho que se formou após o final da Segunda Guerra Mundial, atualizada com base em orientações de gestão de pessoas menos autoritárias e mais integradas aos aspectos "psicológicos" do trabalhador, isto é, às orientações constituídas em acordo com a filosofia das "relações humanas", Carlson apresentou as relações públicas aos membros do Idort como a atividade que poderia ajudar a administrar o "fator humano" nas relações de trabalho.

Foram três as conferências concedidas pelo norte-americano aos membros do instituto na ocasião de sua vinda ao Brasil. Carlson havia sido convidado para ministrar um curso específico de relações públicas na Escola Brasileira de Administração Pública (Ebap) da Fundação Getúlio Vargas, localizada na cidade do Rio de Janeiro, estendendo sua estadia a convite de membros do instituto, para visita à cidade de São Paulo. Com o apoio da empresa São Paulo Tramway, Light and Power Co. Ltd. (futura Eletropaulo), o Idort promoveu as seguintes palestras de Eric Carlson nos dias 6, 7 e 10 de julho de 1953, no auditório do Banco Nacional Interamericano: (1) 0 papel das relações públicas na racionalização do trabalho; (2) Relações públicas e suas responsabilidades na administração e organização administrativa; e (3) Criação de um clima de opinião pública favorável à produtividade e ao trabalho de cooperação entre a administração e os trabalhadores.

Já na França, em 1951, Lucien Matrat, em parceria com Alec Carin, publicou uma obra considerada pioneira no contexto dos estudos sobre as relações públicas. Intitulado Les public-relations: moteur de productivité, esse livro procurou mostrar argumentos que, segundo seus autores, poderiam demonstrar a relação direta entre a atividade de relações públicas e o aumento de produtividade nas empresas. Convém notar que, dentro desse propósito, tal publicação traz questões que revelam, de certa forma, o entendimento que se demonstrava à época sobre as orientações de relações públicas no tocante à administração das relações de trabalho. 
Pode-se dizer que as recomendações de relações públicas difundidas por Eric Carlson, no Brasil, e por Lucien Matrat, na França, fazem parte de um contexto mais abrangente de orientações de comunicação nas relações de trabalho em organizações, que foram produzidas e postas em circulação por um conjunto de indivíduos e instituições num momento decisivo de (re)configuração da racionalização do trabalho em ambos os países.

O material produzido pelo Idort, pelo Cnof e pela Cegos - levantado em nossa pesquisa - indica uma série desses ditames de relações públicas adequados aos princípios da racionalização do trabalho. Trata-se de preceitos que procuram conceber um conjunto de valores sociais e de regras de comportamento aos trabalhadores, dos mais diversificados níveis hierárquicos. Estamos falando de "prescrições" que compõem o discurso de comunicação nas relações de trabalho em organizações, produzidas no embate de relações de produção e de força engendrado em condições socioeconômicas e políticas determinadas pelo curso da história. Isto é, são enunciados compostos, dispostos e difundidos em campos de trocas simbólicas, materializados em discursos que, no caso de nosso estudo, são representativos de um tipo de compreensão sobre a gestão da comunicação atrelada aos princípios da racionalização do trabalho em empresas.

Tendo isso em vista, tratar de prescrições de relações públicas é falar de recomendações e orientações consideradas obrigatórias para a conformação de um determinado modo de pensar e ordenar as relações sociais em situações de trabalho.

Yves Schwartz e Louis Durrive (2010, p. 68) explicam que a realização do trabalho demanda sempre "um prescrito, um conjunto de objetivos, de procedimentos, de regras - relativos aos resultados esperados e às maneiras de obtê-los. Quem prescreve? Em termos gerais, é a sociedade quem prescreve".

Admitir que é a sociedade quem prescreve o trabalho é levar em conta que o trabalhador está sempre suscetível às várias pressões e injunções, de origens variadas, que influenciam os objetivos a serem alcançados e as formas de consegui-los na realização do trabalho (Daniellou, 2002).

As prescrições de relações públicas, alinhadas a essa abordagem, podem ser consideradas prescrições sob o "modo de pensar", conforme ideia pensada originalmente por François Daniellou (2002).

Sob essa perspectiva, apresentaremos, de modo sucinto, algumas dessas prescrições identificadas no corpusde nossa pesquisa.

No que diz respeito aos textos publicados pelo Cnof e pela Cegos, observa-se uma série de posicionamentos políticos compartilhados entre seus produtores. Seus modos de conceber a vida em sociedade denunciam uma ideologia integrada à tentativa de escamotear os conflitos presentes nas relações entre capital e trabalho. Percebe-se um cenário construído em torno de ditames progressistas e civilizatórios que conduzem a pontos de vista defendidos como positivos para o bem-estar do homem na sociedade. Porém, o confronto entre os indivíduos é reprovado e contesta-se, num cunho plenamente moralista, qualquer comportamento ou atitude que possa lançar discórdia na sociedade e nas empresas. Existe uma tentativa contínua de evitar situações de tensão. Ao mesmo tempo, reivindica-se mais atenção às condições dos indivíduos nas organizações, àqueles que propiciam sua existência e o seu funcionamento. As recomendações quanto ao tratamento que deve ser dado aos trabalhadores são formuladas em torno de ditames como: mais atenção às suas necessidades psicológicas, mais respeito e dignidade, menos atitudes autoritárias e coercitivas. É como se houvesse um desejo generalizado de criar nas organizações, um contexto livre de agitações e de perturbações. Seria a formulação de um ambiente de harmonia, em que os indivíduos possam concentrar todos os seus esforços na realização de seu trabalho de modo a serem o mais eficazes possível. 
A atividade de relações públicas e o uso da comunicação nas organizações são apropriados como uma maneira eficiente de acomodar e fazer valer todas essas condições em favor de uma conjuntura pensada a partir dos princípios da racionalização do trabalho.

Dentre as prescrições identificadas no material francês são recorrentes as seguintes: 1) apelo à "verdade", ou seja, as relações entre os homens na sociedade, entre o Estado e os cidadãos, entre empresas e trabalhadores deveriam estar pautadas por uma espécie de honestidade e de transparência; 2) objetividade da informação; 3) funcionário permanentemente informado sobre o funcionamento da empresa; 4) diálogo entre trabalhadores e 0 comando das organizações e entre chefias e subordinados; 5) a atividade de relações públicas e a comunicação consideradas um novo meio de administração da empresa.

No que se refere ao material brasileiro, em especial às apostilas oriundas dos cursos de relações públicas promovidos pelo Idort, pensamos em seis categorias de análise das prescrições de relações públicas oriundas da análise do corpus em questão que, a nosso ver, são capazes de potencializar reflexões fundamentais quanto à constituição dessas prescrições em relação ao discurso de racionalização do trabalho difundido e legitimado pelo Idort no Brasil.

As categorias de análise propostas foram as seguintes: 1) relação entre as organizações e seus empregados por meio de interesses mútuos; 2) "boas relações" entre chefias e subordinados; 3) identificação dos interesses dos trabalhadores; 4) garantia de compreensão das informações transmitidas pela empresa aos trabalhadores; 5) integração do trabalhador ao ambiente das organizações; 6) fases do planejamento da atividade de relações públicas no contexto da organização e gestão do trabalho.

Em linhas gerais, o desenvolvimento dessas categorias demonstra determinados pontos em comum no que diz respeito ao uso prescrito da comunicação na administração das relações entre trabalhadores e o comando das organizações, sendo que a apologia da doutrina das "relações humanas" ganhou destaque dentro desse contexto.

É sabido que os princípios das "relações humanas" foram retomados pelo discurso da racionalização do trabalho, a partir da segunda metade dos anos 1940, de modo a conduzir, em grande medida, o próprio discurso do ldort nas duas décadas seguintes. A filosofia propagadora do "fator humano" no trabal ho trouxe novos elementos para a argumentação dos agentes da racionalização, em benefício de um maior controle social dos trabalhadores nas organizações. E, como é discutido em nossa pesquisa de doutorado, a filosofia das relações públicas encontrou-se com os ditames das "relações humanas" no próprio discurso da racionalização difundido pelo Idort. Nossa análise procurou mostrar que os princípios das "relações humanas" estariam bem conectados à noção de relações públicas.

\section{CONSIDERAÇÕES FINAIS}

De acordo com o que indicamos no início deste artigo, nosso principal propósito foi discorrer sobre os ditames que orientaram a constituição das prescrições de relações públicas identificadas no material brasileiro e francês levantado e analisado em nossa pesquisa de doutorado.

Diante disso, mesmo que de maneira sintética, falamos e procuramos refletir sobre as filosofias de trabalho constituintes do processo de racionalização do trabalho que guiaram a gestão da comunicação nas relações de trabalho em organizações, na primeira metade do século XX. No caso, tratamos dos preceitos tayloristas, fordistas e da Escola das Relações Humanas. Ademais, abordamos algumas das prescrições de relações públicas identificadas e analisadas em nossa tese. 
Certamente, um entendimento mais amplo e aprofundado sobre a pesquisa pode ser alcançado com a leitura da tese em sua íntegra. De qualquer forma, entende-se que a apresentação - mesmo que introdutória - do objeto de estudo e do corpus da pesquisa realizada pode contribuir para dois pontos considerados por nós fundamentais para o avanço das pesquisas científicas sobre a gestão da comunicação no trabalho em organizações: 1) investigações de cunho histórico, por meio de identificação e análise de documentos primários, são valiosas para melhor compreendermos as bases constitutivas dos discursos do tempo presente; e 2) tratar de gestão da comunicação nas relações de trabalho em organizações demanda uma relação mais próxima com os temas do mundo do trabalho, ainda ignorados por significativa parte dos estudiosos do campo da comunicação interessados na questão.

\section{REFERÊNCIAS}

BRAVERMAN, Harry. Trabalho e capital monopolista. Rio de Janeiro: Zahar, 1987.

CARIN, Alec; MATRAT, Lucien. Les public-relations: moteur de productivité. Paris: Éd. Elzevier, 1951.

DANIELLOU, François. Le travail des prescriptions. In: Actes du 37ème Congrès de la Self, "Les évolutions de la prescription". Conférence inaugural. Aix-en-Provence, 2002. Disponível em: < http://www.ergonomie-self.org/self2002/daniellou.pdf >. Acesso em: jan. 2011.

DESMAREZ, Pierre. La sociologie industrielle aux États-Unis. Paris: Armand Colin, 1986.

GRAMSCI, Antonio. Americanismo e fordismo. São Paulo: Hedra, 2008.

HELOANI, José Roberto. Organização do trabalho e administração: uma visão multidisciplinar. 2. ed. São Paulo: Cortez, 1996.

ORLANDI, Eni Puccinelli. Análise de discurso: princípios e métodos. Campinas, SP: Pontes, 1999.

PILLON, Thierry; VATIN, François. Traité de sociologie du travail. Toulouse: Octares, 2007.

REBECHI, Claudia Nociolini. Prescrições de comunicação e racionalização do trabalho: os ditames de relações públicas em diálogo com o discurso do Idort (anos 1930-1960). 2014. 351 f. Tese (Doutorado em Ciências da Comunicação). Escola de Comunicações e Artes, Universidade de São Paulo, São Paulo, Brasil, 2014.

SCHWARTZ, Yves; DURRIVE, Louis. Trabalho e ergologia. 2. ed. Rio de Janeiro: Eduff, 2010.

TAYLOR, Frederick W. Princípios da administração científica. São Paulo: Atlas, 1978.

. Comment réconcilier patronset travailleurs:extraits de The principles of scientific management, traduits, présentés et annotés par Igor Martinache. Paris: Alternatives Économiques, 2013.

VARGAS, Nilton. Gênese e difusão do taylorismo no Brasil. In: Ciências sociais hoje. Anuário de antropologia, política e sociologia. São Paulo: Anpocs/Cortez, 1985. p.155-190.

Artigo recebido em 21.9.2015 e aprovado em 3.10.2015. 